\title{
Relevance of adding a triangular dynamic cushion on a traditional chair: A 3D-analysis of seated schoolchildren
}

\author{
T. Fettweis ${ }^{\mathrm{a}, *}$, M.N. Onkelinx ${ }^{\mathrm{a}}$, C. Schwartz ${ }^{\mathrm{a}, \mathrm{b}}$, C. Demoulin ${ }^{\mathrm{a}, \mathrm{c}}$, J.L. Croisier ${ }^{\mathrm{a}, \mathrm{b}, \mathrm{c}}$, \\ M. Vanderthommen ${ }^{\mathrm{a}, \mathrm{b}, \mathrm{c}}$ \\ a Department of Sport and Rehabilitation Sciences, University of Liege, Allée des Sports 4, 4000, Liege, Belgium \\ b Laboratory of Human Movement Analysis (LAMH), University of Liege, Allée de la Découverte 13A, 4000 Liège, Belgium \\ ${ }^{c}$ Department of Physical Medicine and Rehabilitation, Liège University Hospital (CHU), Avenue de l'Hopital 1, 4000, Liege, Belgium
}

\section{A R T I C L E I N F O}

\section{Keywords:}

Back pain

Ergonomics

Schoolchildren

Sitting position

Electromyography

3D-analysis

\begin{abstract}
A B S T R A C T
Background: Low back pain is highly prevalent in the general population and is even reported as early as at primary school. A poor sitting position has been suggested as an etiologic factor. This study analysed, in primary schoolchildren, the influence of a triangular dynamic cushion that aims to help children maintain their physiological lumbar lordosis and to induce movement to reduce the static effect of the sitting position.

Methods: Thirty 8-year-old children took part in this study. A 3D analysis combined with electromyography was used to evaluate the biomechanics and the related muscle activation in two sitting positions (with and without a triangular cushion on a horizontal stool) during a 15-minute working task. In addition, the force of the feet on the ground was assessed with a force plate.

Findings: The cushion improved the trunk-thighs angle, lumbar lordosis, anterior pelvis tilt, and feet support on the ground $(p<0.0001)$. In addition, sitting on the cushion appeared to be more dynamic $(p<0.05)$ and induced a decrease of the lumbar paravertebral muscle activity $(p<0.01)$.

Interpretation: Sitting on a dynamic triangular cushion tends to favour the "ideal" siting position usually described in the literature and to decrease the level of paravertebral muscle recruitment. Seeing that sitting position is a risk factor to develop low back pain, the cushion could be a solution to prevent it.
\end{abstract}

\section{Introduction}

From as early as the first year of elementary school, pupils spend about a thousand hours a year sitting, most of the time, upon unsuitable furniture (Cardon et al., 2004; Troussier, 1999).

Since 1884, European standards for furniture have been based on the recommendations of the orthopaedic surgeon Staffel, according to whom the best sitting position (SP) is one with ankles, knees, and hips flexed at $90^{\circ}$ (Hamimi, 2008). Although they remain controversial (Davis et al., 2009; Macedo et al., 2015), several studies since the 1950s have reported the influence of SP on lumbopelvic posture and back complaints (Burton and Eriksen, 2004): traditional furniture increases the posterior tilt of the pelvis and results in an angle between trunk and thighs (trunk-thighs angle) of $90^{\circ}$ or less (Lord et al., 1997). This posterior tilt tends to increase the intra-discal pressure even more when the feet do not touch the ground (Claus et al., 2009). Unfortunately, actively maintaining the physiological curves of the spine oneself on traditional furniture is difficult and requires a high level of muscular activity (Caneiro et al., 2010; Waongenngarm et al., 2016). In 1981, Mandal recommended a position with a $135^{\circ}$-trunk-thighs angle in order to favour the physiological lumbar lordosis (Mandal, 1981). Since then, it is recommended that furniture be adapted by raising the seat and inclining it forward in order to reach this reference angle (Bejia et al., 2005; Saarni et al., 2007a, 2007b). However, this recommendation does not take into account the fact that dynamism is also essential in SP. In fact, in a purely static SP, the flow of fluid from the discs may be reduced or reversed (Claus et al., 2009). In addition, prolonged static SP is associated with muscular inactivity that could induce muscular weakening (Baumgartner et al., 2012) with an eventual impact on lumbar proprioception (Dolan and Green, 2006) and consequently more risk of injuries (Hodges and Moseley, 2003).

Nowadays, several types of ergonomic school furniture in accordance with Mandal's criteria and dynamic criteria exist. However, due to financial issues, only a few schools have the opportunity to buy such ergonomic furniture. Therefore several authors (Fedewa and Erwin, 2011; Frères and Mairlot, 2002; Wu et al., 1998) have simply

\footnotetext{
* Corresponding author at: Quartier Blanc Gravier, Allée des Sports 4, 4000 Liège, Belgium.

E-mail address: tfettweis@ulg.ac.be (T. Fettweis).
} 
suggested adding a triangular pelvic support on the chair to facilitate the opening of the trunk-thighs angle and consequently the anterior tilt of the pelvis and the physiological curves of the spine. Others authors have also recommended the use of a disc inflated with air to increase dynamism in SP (Erwin et al., 2016; Fedewa and Erwin, 2011; Gregory et al., 2006). The cushion (Movin'Sit ${ }^{\circledR}$ ) used in the present study was developed to combine the triangular form with dynamism.

Considering the scant literature on the topic, investigating the impact of this dynamic triangular cushion on schoolchildren's SP appears particularly relevant. The first hypothesis of this study was that schoolchildren's SP can be improved simply by using this cushion, which could facilitate the opening of the trunk-thigh angle and induce movements that would reduce the static effect of the SP. A second hypothesis was that sitting on the cushion could reduce the global activation of muscles in response to SP improvement.

\section{Materials and methods}

Thirty children aged eight years (mean age (SD): 7.8 (0.4) years; mean height (SD): 129.29 (6.15) cm; mean weight (SD): 28.31 (7.01) $\mathrm{kg}$ ) were invited to participate in the present study with the informed consent of both the children and their parents. The inclusion criteria were that the children had to have been born in 2008, had to be in second elementary school and did not suffer from any know skeletal deformations or neurological problems. The experimental protocol was approved by the Medical Ethics Committee of the University of Liège. It consisted of a one-hour session in the Laboratory of Human Motion Analysis (LAMH) of the University of Liège, Belgium. The children's SP was analysed with and without a triangular dynamic cushion added on "traditional" school furniture (Fig. 1). The furniture included a table (mean height (SD): $63(2) \mathrm{cm}$ ) and a stool (mean height (SD): $39(2) \mathrm{cm}$ ) whose dimensions were in accordance with the European norms NF EN 1729-1 (D 60-603-1) and NF EN 1729-2 (D 60-603-2) (AFNOR, 2006). The rubber triangular dynamic cushion (Movin'Sit@): $7 \times 25 \times 30 \mathrm{~cm}$ ) was inflated with air so as to have a correct consistency, but not overfilled (seen by a rounded surface). Therefore, every child was evaluated on the same furniture, which was not adaptable to the child's height.

No explanation of how to use the cushion was given. Children were only asked to sit on the furniture and to fill in an entertaining exercise book for 15 min under both conditions, which took place in a random order, separated by a five-minute period of free motion. Seven 15-s recordings were made every $2 \mathrm{~min}$ in both conditions so that we could analyse the evolution of SP over time in a multiparametric manner: in fact we combined and synchronized 3D, electromyographic (EMG), and dynamographic analyses.

\subsection{D analysis}

We used a 3D optoelectronic system (Codamotion $^{\mathrm{TM}}$, Charnwood Dynamics, Rothley, UK) to measure the SP characteristics. We tracked the 3D position of the child's head, trunk, pelvis, and legs with 17 markers and four Codamotion CX1 units. The acquisition rate was $100 \mathrm{~Hz}$. The markers were positioned on the head $(n=2$ : side edge of both eyes), along the spine ( $n=7$ : occiput, top of the cervical curvature, C7/D1, top of the dorsal curvature, D12/L1, top of the lumbar curvature, L5/S1), on the pelvis ( $n=4$ : both PSIS and ASIS), and on both legs ( $n=4$ : trochanter, external knee joint spacing, external malleolus, metacarpal bone V) (Fig. 2). The placement of the markers enabled us to measure different angles: head inclination ( $\mathrm{a}=$ angle between the plan of the eyes and the horizontal), trunk inclination ( $b=$ angle between the c7/D1-L5 line and plan of the pelvic), pelvis inclination ( $c=$ angle between the ASIS line and the horizontal), head tilt ( $\mathrm{d}=$ angle between the both eyes-C7 plan and the horizontal), cervical lordosis ( $\mathrm{e}=$ angle formed by the markers occiput, top of the cervical curvature and C7/D1), dorsal kyphosis ( $\mathrm{f}=$ angle formed by the markers $\mathrm{C} 7 / \mathrm{D} 1$, top of the dorsal curvature and D12/L1), lumbar kyphosis ( $\mathrm{g}=$ angle formed by the markers D12/L1, top of the lumbar curvature and L5/S1), pelvis tilt (h: angle between the plan of the pelvic and the horizontal), and trunk-thighs angle ( $\mathrm{i}=$ angle between the $\mathrm{C7} /$ D1-L5/S1 line and the trochanter-knee line) (Fig. 3). We calculated the mean angles for each period of registration of $15 \mathrm{~s}$ and we calculated the absolute values for the head, trunk, and pelvis inclinations. In addition, the dynamism of the SP was evaluated with the standard deviation of each parameter during each registration of $15 \mathrm{~s}$ : a large standard deviation indicate more movements to either side of the mean position.

\subsection{EMG analysis}

We measured the muscular activity of the lumbar, abdominal, and quadriceps muscles with six EMG electrodes (Trigno, Delsys, Massachusetts, USA) placed in accordance with the recommendations of Halaki and Ginn (Halaki and Ginn, 2012) (Fig. 2). EMG data were sampled at $1000 \mathrm{~Hz}$. The raw data were first digitally filtered using a zero-lag fourth-order Butterworth filter with cut-off frequencies set at
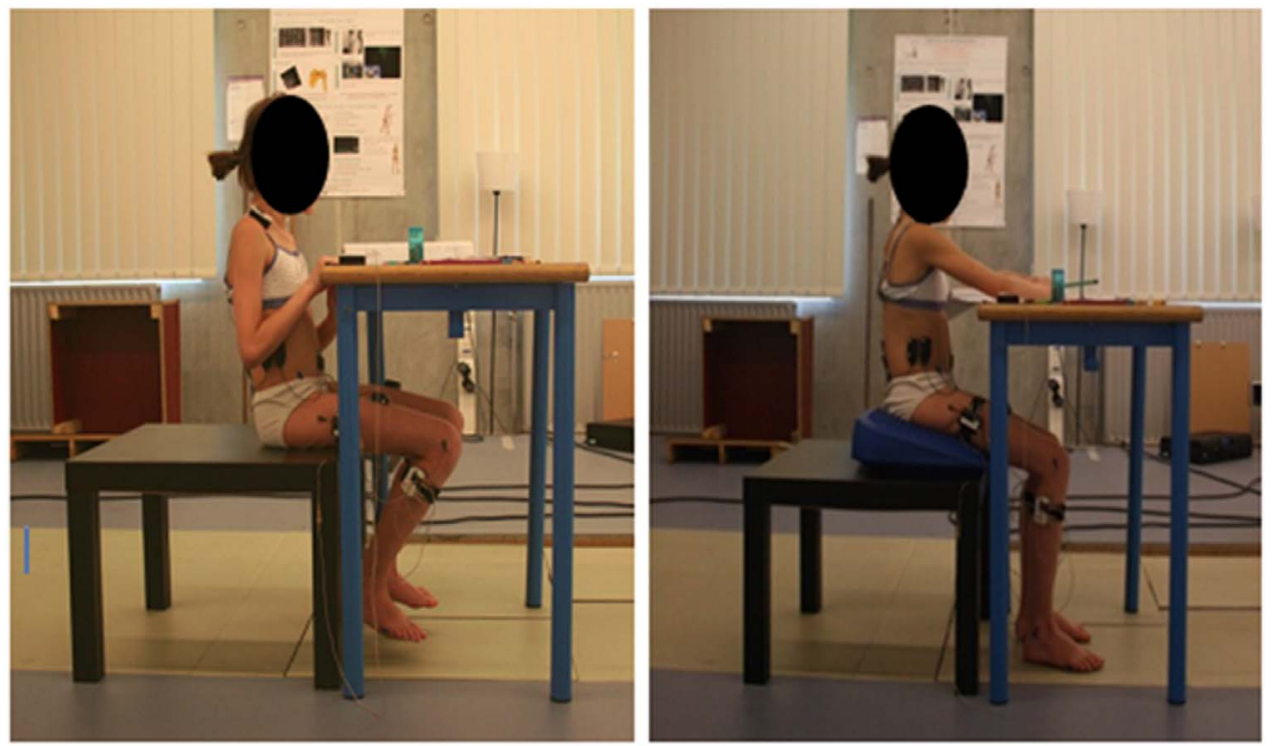

Fig. 1. Illustration of one child's sitting position in the experimental conditions with and without the dynamic triangular cushion. 


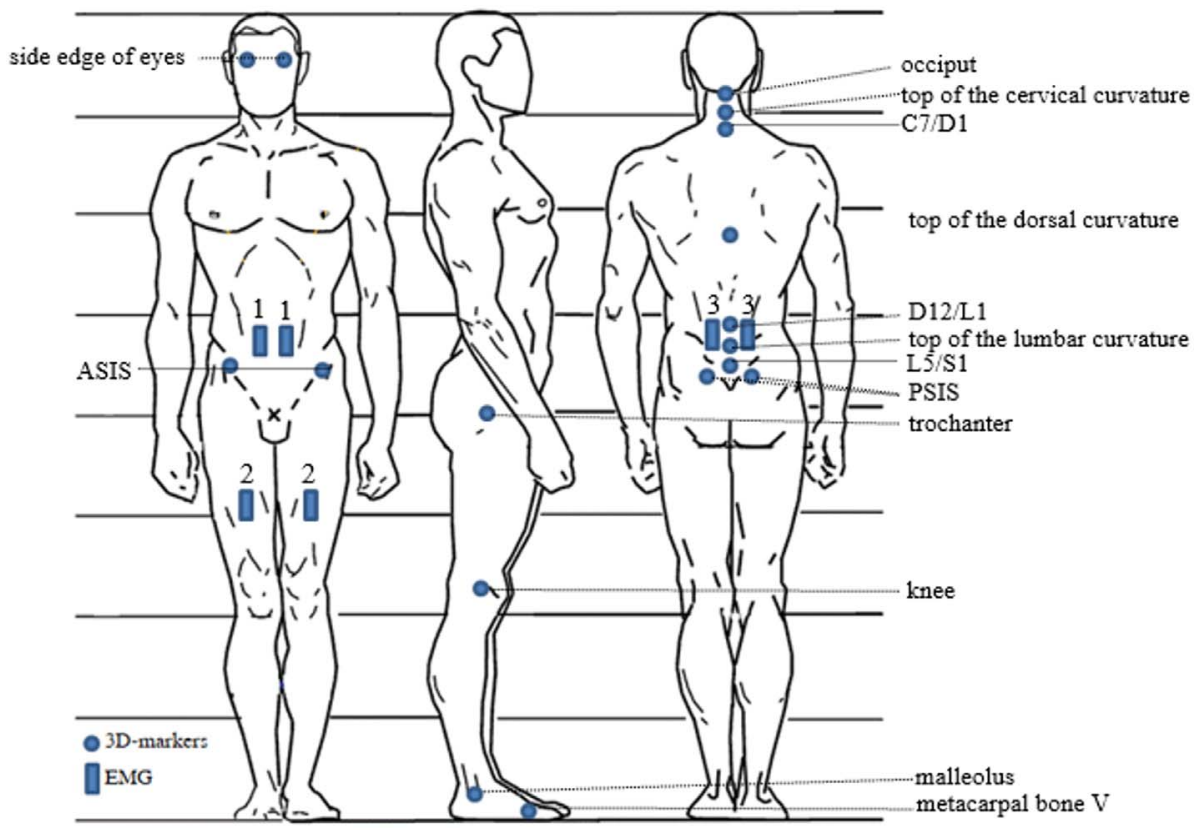

Fig. 2. Placement of 3D-markers and EMG electrodes. ( 1 = abdominal muscle; $2=$ quadriceps; $3=$ lumbar muscle).
10 and $500 \mathrm{~Hz}$. The root mean square of the data was then computed using a time window of $100 \mathrm{~ms}$. The muscle activity was expressed in terms of amplitude as a percentage of the maximal voluntary contraction (MVC), which constitutes the most reliable reference to compare the muscular activities of different people (Halaki and Ginn, 2012) and in terms of the duration of activation above a given threshold (duration of muscle activity superior to $5 \%$ of the MVC) (Okada, 1972). The MVC evaluations were performed at the beginning of the session and were preceded by a warm-up consisting of dynamic exercises involving the specific muscle and three sub-maximal isometric contractions in the same conditions as the test. The MVC evaluation consisted of three maximal isometric contractions of $5 \mathrm{~s}$ with $2 \mathrm{~min}$ of rest between each trial to avoid tiredness (Mathiassen et al., 1995). Lumbar paravertebral muscles were assessed with the child lying prone and with two manual resistances respectively placed between the scapula and on the posterior face of the thighs. For the abdominal MVC assessment, the child sat on a physiotherapist's table with the backrest inclined at $30^{\circ}$ and the knee flexed at $90^{\circ}$. The resistance was applied on the ankles and the thorax. The quadriceps force was assessed in the SP with knee and hip flexed at $90^{\circ}$. The resistances were placed in the middle of the tibia and on the thigh. Both legs were assessed successively. For each MVC evaluation, the children were asked to exert force as hard as they could and were encouraged verbally by the evaluator. The MVC of each muscle was defined as the highest EMG peak of the three trials.

\subsection{Dynamographic analysis}

The force applied by the feet on the ground was measured during the SP with one force plate of $60 \mathrm{~cm} \times 40 \mathrm{~cm}$ (Kisler ${ }^{\mathrm{Tm}}$ type $9281 \mathrm{EA}$, Kisle AG, Switzerland). The mean vertical ground reaction forces acquired during each 15-s registration were normalized with respect to the children's body weight.

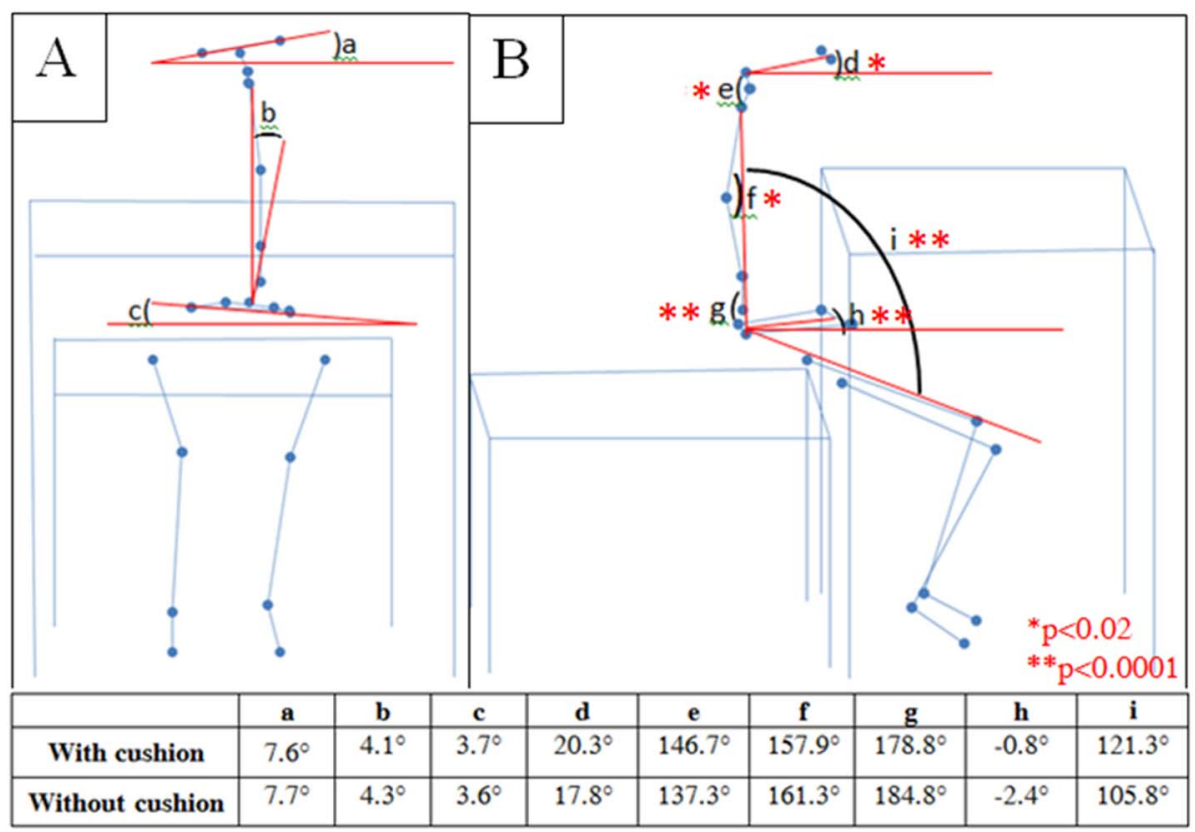

Fig. 3. Children $(n=30)$ 's mean segmental angles in SP when using (with cushion) or not (without cushion) a triangular dynamic cushion. Panel A and B: illustration of the different angles (mean values in the "with cushion" condition) (panel A = frontal view and panel B = sagittal view). ( $\mathrm{a}=$ head inclination; $\mathrm{b}=$ trunk inclination; $\mathrm{c}=$ pelvis inclination; $\mathrm{d}=$ head tilt; $\mathrm{e}=$ cervical lordosis, $\mathrm{f}=$ dorsal kyphosis; $\mathrm{g}=$ lumbar kyphosis; $\mathrm{h}=$ pelvis tilt (negative values of " $\mathrm{h}$ " correspond of a posterior pelvic tilt), $\mathrm{i}=$ trunk-thighs angle). $\left({ }^{*} p<0.02 ;{ }^{* *} p<0.0001\right)$. 


\subsection{Statistical analysis}

The statistical analysis was carried out using the statistical software "R" (version 3.3.0). Basic descriptive statistics and frequency tables were used to calculate the means, standard deviations, extreme values, and percentages. The normal distribution was verified with the ShapiroWilk test. A two-way repeated measure ANOVA was used to analyse the time effect. A student's $t$-test for paired samples was used to compare the child's SPs on both types of furniture. Significant results were determined as $p<0.05$.

\section{Results}

The SPs of 30 children were registered during 7 periods of $15 \mathrm{~s}$ for both types of furniture.

\subsection{D-analysis}

A first analysis constituted to analyse the time course of the different measured angles. This revealed that the time effect was not significant $(p>0.37)$. So we could globalize the seven periods of registrations and calculate, for each angle, a mean value reflecting the entire registration period (105 s) (Fig. 3).

Our results indicate that the trunk-thighs angle and the anterior pelvis tilt are significantly higher when using the cushion than without using it $(p<0.0001)$. While a lumbar kyphosis was observed without the cushion, lumbar lordosis was present when using it ( $\mathrm{p}<0.0001$ ). Our results also indicated that head tilt decreased significantly $(p=0.02)$, cervical lordosis decreased significantly $(p=0.01)$, and dorsal kyphosis increased significantly $(\mathrm{p}=0.01)$ when children were seated on the triangular cushion (Fig. 3).

Taking into account that the time effect was not significant between the seven registration periods, the dynamism of the SP (reflected by the standard deviation) was evaluated over the entire registration period (105 s) (Fig. 4). Globally, the pelvic inclination was the more stable angle $\left(\mathrm{SD}<2^{\circ}\right.$ ) and cervical lordosis was the more unstable one (SD $>8^{\circ}$ ). On comparing both conditions, there were significantly more movements to either side of the mean posture for pelvic inclination $(p=0.04)$ and tilt $(p=0.01)$ and for lumbar lordosis $(p=0.03)$ when using the cushion (Fig. 4).

\subsection{EMG analysis}

Considering that the time effect was not significant, we were able to globalize the seven periods of registrations and to calculate the mean values reflecting the entire registration period (105s) (Table 1).

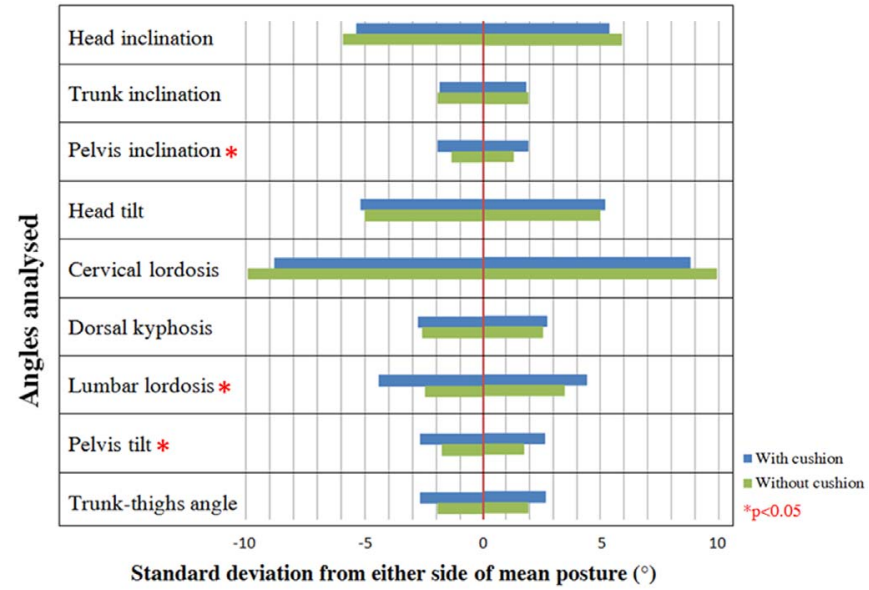

Fig. 4. Mean of standard deviation of children's segmental angles in SP when using "traditional" furniture with and without the cushion, respectively ( ${ }^{*} p<0.05$ ).
Table 1

Mean intensity (m(SD)) and duration of activation (m(SD)) of lumbar paravertebral, abdominal and quadriceps muscles when sitting respectively on the "traditional" furniture with and without the cushion.

\begin{tabular}{lllll}
\hline Activity & Muscle & With cushion & $\begin{array}{l}\text { Without } \\
\text { cushion }\end{array}$ & $p$ \\
\hline Mean intensity (\%MVC) & $\begin{array}{l}\text { Lumbar } \\
\text { paravertebral }\end{array}$ & $4.3(0.3)$ & $5.1(0.7)$ & $0.002^{*}$ \\
& $\begin{array}{l}\text { Abdominal } \\
\text { Quadriceps }\end{array}$ & $2.8(0.1)$ & $2.7(0.5)$ & 0.32 \\
& $\begin{array}{l}2.5(0.7) \\
\text { Lumbar }\end{array}$ & $30.2(2.4)$ & $36.5(4.5)$ & 0.12 \\
Duration of & paravertebral & & & $0.006^{*}$ \\
MVC (\%time) & Abdominal & $15.2(3.1)$ & $12.6(1.9)$ & 0.09 \\
& Quadriceps & $7.9(0.6)$ & $7.4(1.7)$ & 0.43 \\
\hline
\end{tabular}

${ }^{*} p<0.05$

Globally, in our experimental conditions, the recruitment of the different evaluated muscles was low ( $<5 \%$ of MVC). The EMG analysis also suggested a decrease of paravertebral muscle recruitment in terms of intensity $(p=0.002)$ and of duration above the 5\% MVC threshold $(p=0.006)$ when using the cushion.

\subsection{Dynamographic analysis}

As there was no significant time effect, we were able to globalize the seven periods of registrations and to calculate mean values reflecting the entire registration period (105 s). Every child was able to touch the ground from both types of furniture. However, children supported the feet on the ground more when sitting on the cushion than without the cushion. Objectively, the mean ground reaction force increased significantly when children were sitting on the cushion (18\% of the body weight with the cushion VS $12.3 \%$ of the body weight without the cushion $-p<0.0001$ ).

\section{Discussion}

The present study, which aimed at investigating the influence of simply adding a triangular dynamic cushion when using school furniture, indicated that this cushion could improve the quality of the SPs of schoolchildren. Other studies found the same results when children sat on other types of furniture like the Back-App ${ }^{\circledR}$ which also combines dynamism with a tilted seat (O'Sullivan et al., 2012a). However, this type of chair does not include a backrest, which is crucial for the prevention of low back pain because its use tends to reduce intra-discal pressure (Knight and Noyes, 1999; Wilke et al., 2001). In the real conditions of the classroom, simply adding the cushion on the chair makes it possible to conserve the backrest and to sit in working (without backrest contact) and listening (with backrest contact) postures. Stability balls also combine both properties of the cushion and are regularly used in classrooms (Erwin et al., 2016; Fedewa et al., 2015; Fedewa and Erwin, 2011; Gregory et al., 2006; Jackson et al., 2013). However, their efficiency in improving SP is disputed and they seem to be more of a gymnastic accessory than a chair on which one can sit for a long time in the classroom (Gregory et al., 2006; Mc Gill et al., 2006).

Schoolchildren spend thousands of hours a year in SPs. Considering that SPs may be an important risk factor for low back pain for them (Burton and Eriksen, 2004; Cardon and Balagué, 2004), the quality of the SP should be taken into consideration at primary school. Previous studies related to the influence of school furniture on SP were exclusively focused on teenagers (Cardon and Balagué, 2004), while children have to get used to sitting on school furniture as soon as primary school starts (Cardon et al., 2002). Therefore, this study involved younger schoolchildren (eight years old) in order to explore the crucial period when bad habits could be acquired.

Several methods exist to evaluate SP. The first studies used video 
recording (Murphy et al., 2002) or photography (Annetts et al., 2012; Koskelo et al., 2007). However, these are not the best ways because they only allow relatively inaccurate 2D analysis of the child's position. The portable ergonomic observation method (Cardon et al., 2004; Geldhof et al., 2006; Murphy et al., 2002) constitutes a pertinent tool for recording changes in SP. However, this assessment is not very accurate because it cannot detect segmental movements smaller than $20^{\circ}$. In contrast, a 3D-evaluation is very accurate, with a motion detection threshold of $\sim 1^{\circ}$ (Ellegast et al., 2012).

The SPs of our young subjects without the cushion are in accordance with the findings of previous studies conducted on adolescent or adult subjects (Annetts et al., 2012; Ellegast et al., 2012). Mainly, SP on traditional furniture induces an average trunk-thigh angle of $100^{\circ}$ so that a posterior tilt of the pelvis and lumbar kyphosis appear. As expected, the use of the triangular cushion induced an increase in the trunk-thighs angle, which became closer $\left(120^{\circ}\right)$ to the "ideal" position $\left(135^{\circ}\right)$ described in the literature (Mandal, 1981; O'Keeffe et al., 2013). Its use also resulted in a lower posterior tilt of the pelvis and a lumbar lordosis closer to the physiological curvature. Those improvements could reduce intra-discal pressure, which is an important risk factor for low back pain (Claus et al., 2009). On the other hand, a more adequate lumbo-pelvic position does not always result in a corresponding ideal cervico-dorsal position (Annetts et al., 2012). Indeed, cervical lordosis decreased and dorsal kyphosis increased when using the triangular cushion. This posture probably resulted from the fact that the participants were seated higher with the cushion and therefore had to flex the upper part of the spine more to carry out their exercises, considering that the furniture height was not changed between the two conditions. To avoid this, the use of the cushion in a real condition could ideally be combined with an increase in the table's height and/or tilt (Mandal, 1981, 1984). The second particularity of the cushion used in the present study was that it allowed a dynamic posture, which is often recommended (O'Sullivan et al., 2012c; Sullivan et al., 2006). In fact, dynamic SP could improve the feeding of the inter-vertebral discs due to compression/decompression movements (Claus et al., 2009). In addition, it might reduce muscular weakening induced by muscular inactivity in a long-term static SP (Baumgartner et al., 2012) and improve lumbar proprioception (Dolan and Green, 2006) and thereby reduce the risk of injuries (Hodges and Moseley, 2003). Our results demonstrate that children move significantly more when sitting on the cushion than when sitting on "traditional" furniture. Increased mobility appeared especially at the pelvis and the lumbar spine. This result seems logical because those structures are just above the instable air-inflated cushion. Moreover, the link between pelvis and lumbar spine has already been demonstrated (Annetts et al., 2012; Ellegast et al., 2012; O'Sullivan et al., 2010a, 2010b).

Previous studies suggest that maintaining the spinal physiologic curves in a static SP on traditional furniture needs a high level of lumbar muscular activity (Caneiro et al., 2010; Waongenngarm et al., 2016), which induces fatigue and is incompatible with a long-term posture (Claus et al., 2009). As expected, our EMG analysis demonstrates a decrease of the activation of the lumbar paravertebral muscles on the cushion. This result agrees with the literature that describes a diminution of the activity of those muscles on the same tilted support (Marschall et al., 1995; O'Sullivan et al., 2010a, 2010b; O'Sullivan et al., 2012b; Sabatier, 2014), even if the cushion provides more dynamism in SP. Actually, maintaining static posture is more tiresome than maintaining dynamic posture (O'Sullivan et al., 2012b). On the other hand, as shown in the literature, sitting on the cushion does not change abdominal activity (O'Keeffe et al., 2013; O'Sullivan et al., 2012b, 2012c). Initially, we hypothesized that quadriceps activity could increase the stabilization of the pelvis on the tilted plane (Sabatier, 2014), but this assumption was not confirmed in our subjects. This insignificant result could be explained by the fact that we exclusively evaluated the rectus femoris while other studies showed increased activity in both quadriceps vastus when people sat on tilted seats (Sabatier, 2014).
Finally, few studies have evaluated the natural position of the feet on the ground in SP (Annetts et al., 2012; Ellegast et al., 2012; O'Sullivan et al., 2012a). However, an adequate position and force of the feet on the ground seem essential for the "ideal" SP: they reduce compression of the thighs and thus discomfort, induce better vascular circulation, and reduce intra-discal pressure (Claus et al., 2009). The force plate used in the present study indicated an increase of the force of the feet on the ground when using the cushion and thereby indicated a potentially more comfortable position than that achieved on a traditional chair.

\subsection{Limits}

The chair used in the present study had no backrest so that markers were visible from the 3D measurement units. However, considering that the participants were asked to fill in a ludic exercises book, they spent the whole duration of the study in working SP, so the backrest would probably not have been used (Cardon et al., 2004; Fettweis et al., 2013). As both working and listening SPs are a part of pupils' postural background (Troussier, 1999), an investigation of the listening SP should also be conducted in future studies. Moreover, as this study was performed in a laboratory, we cannot affirm that the seated position always reflected the natural SPs of the schoolchildren in their classroom. Also, no significant change in SP was demonstrated over time in this study. As our investigation period lasted "only" $15 \mathrm{~min}$, we cannot draw any conclusions regarding the positions of the participants after a longer period of sitting. Indeed, teachers often report that schoolchildren begin to slouch during the day. However, investigating the children's SP on furniture during a whole lesson $(2 \times 45 \mathrm{~min})$ would be too long for our young population. Actually, the protocol (preparation included) was already relatively long and it was difficult to keep children's attention longer than that after a full school day. Finally, further studies will be necessary to demonstrate whether the improvement of the SP induced by the triangular dynamic cushion observed in this study has real clinical meaning and can prevent discomfort and back complaints in schoolchildren.

\section{Conclusion}

The present study confirms that using a cushion combining a tilted seat and dynamism has a beneficial impact on the quality of the children's SPs and tends to decrease the level of lumbar muscular activity during sitting. Further studies are needed to confirm these findings and the long-term consequences of utilization of the cushion.

\section{Acknowledgements}

We thank the children who participated in the study and their parents.

\section{Funding}

This research did not receive any specific grant from funding agencies in the public, commercial, or not-for-profit sectors.

\section{References}

Annetts, S., Coales, P., Colville, R., Mistry, D., Moles, K., Thomas, B., van Deursen, R., 2012. A pilot investigation into the effects of different office chairs on spinal angles. Eur. Spine J. 21 (Suppl. 2), S165-70. http://dx.doi.org/10.1007/s00586-012-2189-z. Baumgartner, D., Zemp, R., Stoop, M., Naxera, J., Elsig, J.P., Lorenzetti, S., 2012. The spinal curvature of three different sitting positions analysed in an open MRI scanner. ScientificWorldJournal 19, 400-406.

Bejia, I., Abid, N., Ben Salem, K., Letaief, M., Younes, M., Touzi, M., Bergaoui, N., 2005. Low back pain in a cohort of 622 Tunisian schoolchildren and adolescents: an epidemiological study. Eur. Spine J. 14, 331-336. http://dx.doi.org/10.1007/s00586004-0785-2.

Burton, A., Eriksen, H., 2004. Chapter 2. European guidelines for prevention in low back 
pain: November 2004. Eur. Spine J. 15, S136-168.

Caneiro, J., O'Sullivan, P., Burnett, A., Barach, A., O'Neil, D., Tveit, O., Olafsdottir, K., 2010. The influence of different sitting postures on head/neck posture and muscle activity. Man. Ther. 15, 54-60.

Cardon, G., Balagué, F., 2004. Low back pain prevention's effects in schoolchildren. What is the evidence? Eur. Spine J. 13, 663-679. http://dx.doi.org/10.1007/s00586-0040749-6.

Cardon, G., De Bourdeaudhuij, I., De Clercq, D., 2002. Knowledge and perceptions about back education among elementary school students, teachers, and parents in Belgium. J. Sch. Health 72, 100-106.

Cardon, G., De Clercq, D., De Bourdeaudhuij, I., Breithecker, D., 2004. Sitting habits in elementary schoolchildren: a traditional versus a "Moving school". Patient Educ. Couns. 54, 133-142. http://dx.doi.org/10.1016/S0738-3991(03)00215-5.

Claus, A., Hides, J., Moseley, G., Hodges, P., 2009. Is "ideal" sitting posture real? Measurement of spinal curves in four sitting postures. Man. Ther. 14, 404-408. http://dx.doi.org/10.1016/j.math.2008.06.001.

Davis, J., Dunning, K., Succop, P., 2009. Does ergonomic mismatch at school impact pain in school children? Work 34, 455-464.

Dolan, K., Green, A., 2006. Lumbar spine reposition sense: the effect of a "slouched" posture. Man. Ther. 11, 202-207.

Ellegast, R., Kraft, K., Groenesteijn, L., Krause, F., Berger, H., Vink, P., 2012. Comparison of four specific dynamic office chairs with a conventional office chair: impact upon muscle activation, physical activity and posture. Appl. Ergon. 43, 296-307. http:// dx.doi.org/10.1016/j.apergo.2011.06.005.

Erwin, H., Fedewa, A., Ahn, S., Thornton, M., 2016. Elementary students' physical activity levels and behavior when using stability balls. Am. J. Occup. Ther. 70, 1-7.

Fedewa, A., Erwin, H., 2011. Stability balls and students with attention and hyperactivity concerns: implications for on-task and in-seat behavior. Am. J. Occup. Ther. 65, 393-399. http://dx.doi.org/10.5014/ajot.2011.000554.

Fedewa, A., Davis, M., Ahn, S., 2015. Effects of stability balls on children's on-task behavior, academic achievement, and discipline referrals: a randomized controlled trial. Am. J. Occup. Ther. 69, 1-9.

Fettweis, T., Demoulin, C., Vanderthommen, M., 2013. Influence de la position assise d'enfants sur leurs capacités cognitives. Kinésithérapie 13, 20-25.

Frères, M., Mairlot, M., 2002. Maitres et Clés de la Posture. Frison-Roc. ed, Paris.

Geldhof, E., Cardon, G., De Bourdeaudhuij, I., De Clercq, D., 2006. Effects of a two-schoolyear multifactorial back education program in elementary schoolchildren. Spine (Phila Pa 1976) 31, 1965-1973. http://dx.doi.org/10.1097/01.brs.0000228722. 12968.d2.

Gregory, D., Dunk, N., Callaghan, J., 2006. Stability ball versus office chair: comparison of muscle activation and lumbar spine posture during prolonged sitting. Hum. Factors J. Hum. Factors Ergon. Soc. 48, 142-153. http://dx.doi.org/10.1518/ 001872006776412243.

Halaki, M., Ginn, K., 2012. Normalization of EMG Signals: To Normalize or Not to Normalize and What to Normalize to?.

Hamimi, R., 2008. Enquête auprès des jeunes sur "le dos". Kinésithérapie, la Rev. 8, 35-37. http://dx.doi.org/10.1016/S1779-0123(08)70565-5.

Hodges, P., Moseley, G., 2003. Pain and motor control of the lumbopelvic region: effect and possible mechanisms. J. Electromyogr. Kinesiol. 13, 361-370.

Jackson, J., Banerjee-Guenette, P., Gregory, D., Callaghan, J., 2013. Should we be more on the ball? The efficacy of accommodation training on lumbar spine posture, muscle activity, and perceived discomfort during stability ball sitting. Hum. Factors 55, 1064-1076. http://dx.doi.org/10.1177/0018720813482326.

Knight, G., Noyes, J., 1999. Children's behaviour and the design of school furniture. Ergonomics 42, 747-760. http://dx.doi.org/10.1080/001401399185423.

Koskelo, R., Vuorikari, K., Hänninen, O., 2007. Sitting and standing postures are corrected by adjustable furniture with lowered muscle tension in high-school students. Ergonomics 50, 1643-1656. http://dx.doi.org/10.1080/00140130701587236.

Lord, M., Small, J., Dinsay, J., Watkins, R., 1997. Lumbar lordosis. Effects of sitting and standing. Spine (Phila Pa 1976) 22, 2571-2574.

Macedo, A., Morais, A., Martins, H., Martins, J., Pais, S., Mayan, O., 2015. Match between classroom dimension and students/anthropometry: re-equipment according to European educational furniture standard. Hum. Factors 57, 48-60.

Mandal, A., 1981. The seated man (Homo Sedens) the seated work position. Theory and practice. Appl. Ergon. 12, 19-26.

Mandal, A., 1984. The correct height of school furniture. Physiotherapy 70, 48-53.

Marschall, M., Harrington, A., Steele, J., 1995. Effect of work station design on sitting posture in young children. Ergonomics 38, 1932-1940.

Mathiassen, S., Winkel, J., Hagg, G., 1995. Normalization of surface EMG amplitude from the upper trapezius muscle in ergonomic studies - a review. J. Electromyogr. Kinesiol. 5, 197-226.

Mc Gill, S., Kavcic, N., Harvey, E., 2006. Sitting on a chair or an exercise ball: various perspectives to guide decision making. Clin. Biomech. 21, 353-360.

Murphy, S., Buckle, P., Stubbs, D., 2002. The use of the portable ergonomic observation method (PEO) to monitor the sitting posture of schoolchildren in the classroom. Appl. Ergon. 33, 365-370. http://dx.doi.org/10.1016/S0003-6870(02)00003-0.

Okada, M., 1972. An electromyographic estimation of the relative muscular load in different human postures. J. Hum. Ergol. (Tokyo) 1, 75-93.

O'Keeffe, M., Dankaerts, W., O'Sullivan, P., O'Sullivan, L., O'Sullivan, K., 2013. Specific flexion-related low back pain and sitting: comparison of seated discomfort on two different chairs. Ergonomics 56, 650-658. http://dx.doi.org/10.1080/00140139. 2012.762462.

O'Sullivan, K., O'Dea, P., Dankaerts, W., O'Sullivan, P., Clifford, A., O'Sullivan, L., 2010a. Neutral lumbar spine sitting posture in pain-free subjects. Man. Ther. 15, 557-561. http://dx.doi.org/10.1016/j.math.2010.06.005.

O'Sullivan, K., O'Dea, P., Dankaerts, W., O'Sullivan, P., Clifford, A., O'Sullivan, L., 2010b. Neutral lumbar spine sitting posture in pain-free subjects. Man. Ther. 15, 557-561.

O'Sullivan, K., McCarthy, R., White, A., O'Sullivan, L., Dankaerts, W., 2012a. Lumbar posture and trunk muscle activation during a typing task when sitting on a novel dynamic ergonomic chair. Ergonomics 55, 1586-1595. http://dx.doi.org/10.1080/ 00140139.2012 .721521$.

O'Sullivan, K., McCarthy, R., White, A., O'Sullivan, L., Dankaerts, W., 2012b. Can we reduce the effort of maintaining a neutral sitting posture? A pilot study. Man. Ther. 17, 566-571. http://dx.doi.org/10.1016/j.math.2012.05.016.

O'Sullivan, K., O'Keeffe, M., O'Sullivan, L., O'Sullivan, P., Dankaerts, W., 2012c. The effect of dynamic sitting on the prevention and management of low back pain and low back discomfort: a systematic review. Ergonomics 55, 898-908. http://dx.doi.org/10. 1080/00140139.2012.676674.

Saarni, L., Nygård, C.-H., Rimpelä, A., Nummi, T., Kaukiainen, A., 2007a. The working postures among schoolchildren - a controlled intervention study on the effects of newly designed workstations. J. Sch. Health 77, 240-247. http://dx.doi.org/10. 1111/j.1746-1561.2007.00199.x.

Saarni, L., Nygård, C., Kaukiainen, A., Rimpelä, A., 2007b. Are the desks and chairs at school appropriate? Ergonomics 50, 1561-1570. http://dx.doi.org/10.1080/ 00140130701587368.

Sabatier, P., 2014. Mobilier ergonomique et contraintes biomécaniques subies par le système musculo-squelettique en posture assise. (Toulouse).

Sullivan, P., Dankaerts, W., Burnett, A., Straker, L., Bargon, G., Moloney, N., Perry, M., Tsang, S., 2006. Lumbopelvic kinematics and trunk muscle activity on stable and unstable surfaces. J. Orthop. Sports Phys. Ther. 36, 19-25.

Troussier, B., 1999. Comparative study of two different kinds of school furniture among children. Ergonomics 42, 516-526. http://dx.doi.org/10.1080/001401399185612.

Waongenngarm, P., Rajaratnam, B., Janwantanakul, P., 2016. Internal oblique and transversus abdominis muscle fatigue induced by slumped sitting posture after 1 hour of sitting in office workers. Saf Heal. Work 7, 49-54.

Wilke, H., Neef, P., Hinz, B., Seidel, H., Claes, L., 2001. Intradiscal pressure together with anthropometric data - a data set for the validation of models. Clin. Biomech. 16, 111-126.

Wu, C., Miyamoto, H., Noro, K., 1998. Research on pelvic angle variation when using a pelvic support. Ergonomics 41, 317-327. http://dx.doi.org/10.1080/ 001401398187062. 